\title{
Práticas de letramento digital na escola: o blog como estratégia de ensino e formação de professores
}

\author{
Digital literacy practices at school: \\ The blog as a strategy for teaching and training teachers
}

\author{
Érica de Cássia Maia Ferreira Rodrigues** \\ Luiza Helena Oliveira da Silva**
}

\begin{abstract}
RESUMO: Este artigo, do ponto de vista teórico, ancora-se nos estudos do letramento e da semiótica discursiva, tendo como objetivo principal analisar os usos do digital como estratégia de ensino de leitura e escrita colaborativa, numa turma da educação básica em escola no norte do Tocantins. Como pesquisa participante, mobilizou docentes da escola em oficinas pedagógicas, com a finalidade de apreenderem usos da tecnologia digital no ensino. A intervenção pedagógica mobilizou oito professores da escola-campo, além dos 18 alunos da turma-alvo. Adotaram-se o método dedutivo e como técnicas de coleta de dados: questionários, entrevistas, diário de campo, observação em sala e intervenção pedagógica, bem como áudios transcritos das oficinas. Para análise dos dados, mobilizou-se a semiótica discursiva, privilegiando o nível narrativo e as problemáticas da interação suscitadas pela sociossemiótica. O corpus constituiu-se de entrevistas, produções escritas dos alunos, postagens no blog, transcrições dos áudios das oficinas e um arquivo do Google Docs. Inicialmente, evidenciava-se uma relação de disjunção dos sujeitos-professores e sujeitos-alunos ante a tecnologia digital, seja no que diz respeito aos usos privados, seja no que concerne aos usos escolares. Nessa direção, o trabalho visou a levá-los a superar esse estado disjuntivo, mediante diferentes estratégias.
\end{abstract}

PALAVRAS-CHAVE: Letramento Digital. KEYWORDS: Digital Literacy. TeachingEnsino-aprendizagem. Blog. Discurso. Interação.

\begin{abstract}
This paper is based, from a theoretical point of view, on studies on literacy and discourse semiotics. Its main goals is to analyze the uses of digital media as a teaching strategy for collaborative reading and writing in a middle school class in the North of the State of Tocantins, Brazil. Teachers from the school were gathered in pedagogical workshops with the purpose of learning pedagogical uses of digital technology. The pedagogical intervention joined eight teachers in the school and 18 students in the target classroom. The deductive method was used building on questionnaires, interviews, field journals, classroom observation, pedagogical intervention, and transcript of the workshop audios. Data were analyzed drawing on discourse semiotics and particularly focusing on the narrative level and the interactions issues discussed in socio-semiotics. The corpus consisted of interviews, written productions of students, blog posts, transcripts of workshop audios, and a Google Docs file. The initial results pointed to a disjunctive relationship of students and teachers before the digital technology, both for private uses and for uses at school. Because of this, the work aimed to overcome this disjunctive state through the application of different strategies
\end{abstract} learning. Blog. Speech. Interaction.

\footnotetext{
* Mestra em Letras pelo Programa de Mestrado Profissional em Letras da Universidade Federal do Tocantins UFT. Possui graduação em LETRAS pela Fundação Universidade do Tocantins (2004). Atualmente é Avaliadora Educacional da Rede PCR pela SASE/MEC. Integra o GESTO (Grupo de Estudos do Sentido - Tocantins).

** É mestre e doutora em Letras pela Universidade Federal Fluminense. Em 2013/2014, realizou estágio pósdoutoral em sociossemiótica no Centre de Recherches Politiques (CEVIPOF-CNRS) e Université de Limoges, com bolsa CAPES. Desde 2005, é docente da Universidade Federal do Tocantins, câmpus de Araguaína.
} 


\section{Introdução}

"Eu não queria ocupar o meu tempo usando palavras bichadas de costumes. Eu queria mesmo desver o mundo" Manoel de Barros

O presente artigo é um recorte da dissertação intitulada "Práticas de letramento digital na escola: o blog como estratégia de ensino e formação de professores", e ganha voz a partir da epígrafe que traz três versos do Poema IV do livro "Menino do Mato", do poeta Manoel de Barros. A orientação do poeta para "desver o mundo" soou como um convite, uma vez que parece ser isso que fazemos quando abrimos mão das nossas certezas e nos dedicamos a olhar o Outro, as coisas, os lugares naquilo que o poeta chamaria de estado de ignorância, para quem sabe poder ir além das "palavras bichadas de costumes" ou do olhar preguiçoso que já não vê e não sente mais o mundo. Em seu livro, Manoel de Barros revela o menino Bernardo e a sua infância bonita, e nos fez pensar sobre a possibilidade de reunir a beleza das palavras e o poder de significar que elas têm. Como significar nossa experiência no mundo sem as palavras? Ao final, o neologismo "desver" traduz para nós um exercício que se fez necessário quando buscamos ver de maneira diferente os mesmos sujeitos, as mesmas práticas cotidianas, num contexto para nós tão familiar: o da escola. Por isso mesmo, o primeiro exercício de nossa pesquisa foi o de buscar desver, estranhar o que se apresentava como natural, cotidiano, igual, para posteriormente tentar poder ver sob novas perspectivas e encontrar soluções para os problemas identificados. Que caminhos seriam possíveis?

Muitas foram as motivações para este estudo, mas ressaltaremos aqui duas delas. A primeira foi a necessidade de pensar um projeto de intervenção que representasse uma contribuição efetiva para a escola que elegemos como lócus de pesquisa. Como projeto final do PROFLETRAS, era urgente fazer convergirem as reflexões advindas das muitas disciplinas a uma ação na escola que fosse significativa para os sujeitos. Nesse sentido, diante da ociosidade do laboratório de informática em uma unidade escolar de Araguatins e das dificuldades que identificamos nos docentes quanto a saberes relativos ao digital, pensamos um projeto que contribuísse para novos saberes e práticas escolares mediados pelos usos digitais. Assim chegamos aos gêneros hipermidiáticos e um projeto de criação de um blog. Outra motivação emergiu das discussões no Grupo de Estudos do Sentido do Tocantins (GESTO), ao problematizar à luz da semiótica discursiva diferentes objetos e perspectivas relacionadas a sujeitos e objetos no contexto escolar. Além disso, foi determinante para este estudo pertencer 
ao contexto da escola-campo como docente, conciliando a sala de aula com o cargo de gestora municipal do sistema de ensino de Araguatins.

Tudo isso nos permitiu olhar o contexto escolar sob a perspectiva daquele que ensina atrelado ao diálogo permanente com os docentes que se mostraram sempre receptivos às propostas de intervenção apresentadas. Não se tratou de uma proposta nascida fora da escola, mas dentro dela, e envolvendo os seus sujeitos. O fato é que esse estudo não nasceu de um querer-fazer pessoal, mas de um desejo de aprender e saber-fazer conjunto. Desse modo, movidos pelo desejo de "desver" as coisas, e pelo desejo de contribuir de maneira significativa com o contexto escolar, algumas problemáticas pertinentes ao ensino de leitura e escrita, bem como o uso do digital como estratégia de ensino, se lançaram como norteadoras da pesquisa realizada.

Nossas perguntas de pesquisa foram: O letramento digital compõe as práticas de ensino na escola-campo? Os sujeitos-alunos conhecem e usam a tecnologia em prol da própria aprendizagem? É a escola um espaço que promove o uso da tecnologia digital como instrumento de formação do aluno? O blog poderia se constituir como um lócus de interação favorecendo o desenvolvimento de leitura e da produção escrita? Como um viés interdisciplinar contribuiria para práticas de leitura e escrita? Essas questões guiaram nossa investigação acerca das práticas sociais de leitura e escrita potencializadas pelo uso de recursos digitais. Nesse sentido, partimos do pressuposto de que convergir os interesses dos alunos pelo digital para a produção de objetos de ensino-aprendizagem poderia configurar-se como uma importante estratégia para a otimização de saberes que têm lugar na escola, mas considerando, sobretudo, o que está além dela - os usos da leitura e da escrita demandados pela cultura contemporânea.

Desenvolvemos, então, duas propostas de intervenção pedagógica: a primeira, iniciada em agosto de 2014, objetivou a criação de um blog que serviria para provocar a produção de textos de diferentes gêneros a partir de atividades de leitura e escrita colaborativa. A segundase deu em função dos resultados tímidos obtidos pela primeira, quando, embora tenhamos produzido o blog, consideramos a necessidade de qualificar os professores quanto a usos do digital como estratégia de apoio ao ensino, tendo o computador e a internet como recursos.

Apesar da relevância das concepções teóricas que subsidiaram todo o estudo, daremos destaque aqui ao percurso das intervenções e à análise dos dados. Enfatizamos que os saberes advindos dos estudos do letramento, dos gêneros discursivos, da inter e multidisciplinaridade articulados às contribuições da semiótica como teoria da significação, foram indispensáveis 
para a compreensão da prática pedagógica como um lugar que parece exigir que o professor "desveja" algumas práticas escolares tradicionais, ressignificando-as como forma de atender à necessidade que os sujeitos sociais (alunos) demandam que é aprender novos saberes, e interagir socialmente utilizando-se das novas maneiras de ler e escrever, dos gêneros hipermidiáticos.

\section{Desafios do letramento digital e a escola}

No Brasil, os estudos sobre letramento surgem em meados de 80, sendo paulatinamente absorvidos pelas práticas escolares relacionadas aos efeitos sociais da aquisição e usos da escrita. Aprender e ensinar a partir das demandas sociais é o que se compreende como letramento, que evolve, pois, o conjunto de práticas sociais ligadas à leitura e à escrita em que indivíduos se envolvem em seu contexto social (SOARES, 2012). Nas últimas décadas, sua concepção tornou-se mais plural dada a heterogeneidade dos sujeitos e constantes mudanças sociais a que estamos submetidos. Assim, fala-se em "múltiplos letramentos que variam no tempo e no espaço, mas que são também contestados nas relações de poder" (ROJO, 2009, p. 102).

A instabilidade e fluidez impressa ao modo de viver da sociedade contemporânea tem exigido novas maneiras de comunicação, novas maneiras de ler e escrever, e a isso chamamos novos letramentos e letramentos digitais. Considerando as diferentes práticas e tecnologias que imprimem ao letramento um caráter multimodal, dedicamo-nos ao estudo do letramento digital, compreendido aqui como "um certo estado ou condição que adquirem os que se apropriam da nova tecnologia digital e exercem práticas de leitura e de escrita na tela, diferente do estado ou condição - do letramento - dos que exercem práticas de leitura e de escrita no papel" (SOARES, 2002, p. 151). Essa temática emerge no contexto da escola-campo como uma proposta desafiadora e que convida a refletir sobre a apropriação da tecnologia digital em sala de aula, bem como como suas múltiplas linguagens que nela tem lugar.

O surgimento da tecnologia, além de imprimir novas formas de viver em sociedade, inovou também a maneira de manipular textos orais e escritos e passou a exigir dos sujeitos sociais que aprendessem a ler e escrever utilizando-se de aparelhos como o computador conectado à internet, o celular, e todas as possibilidades que estes trazem. Deste modo, as concepções de leitura e a produção escrita de textos foram também sendo redimensionadas e alcançaram novos espaços que não apenas o da cultura do papel. Essas mudanças configuram o que chamamos letramento digital, ou seja, ler e escrever nas mídias. Esse novo letramento, o 
digital, exige, então, que a escola trabalhe um conjunto de informações e promova situações de aprendizagem que permitam o desenvolvimento de habilidades mentais necessárias para o uso do digital em prol da própria aprendizagem.

Diariamente realizamos eventos/práticas de letramentos nas mais diversas esferas de atividade e com finalidade também distintas. Compreendemos evento de letramento como:

ocasião em que a fala se organiza ao redor de textos escritos e livros, envolvendo a sua compreensão. Segue as regras de usos da escrita da instituição em que acontece. Está relacionado ao conceito de evento de fala, que é governado por regras e obedece às restrições impostas pela instituição (KLEIMAN, 2005, p. 23).

As atividades próprias da vida em sociedade as quais envolvem os seus sujeitos e mobiliza os diferentes saberes constituem-se eventos de letramento. O uso que fazemos de cada um desses eventos nos leva a duas competências essenciais ao ser humano contemporâneo: ler e escrever, através dos quais cultivam e exercem suas práticas sociais (SOARES, 2012).

Ler e escrever na mídia exige as competências e habilidades de leitura e escrita além daquelas relativas às mídias tradicionais. Uma precede a outra e o letramento digital uma nova maneira de dizer, de interagir e aprender. O surgimento de novos suportes tecnológicos para ler redimensiona as práticas de letramento convencionais e dá origem ao letramento digital ou multiletramentos digitais considerando as múltiplas facetas que a tecnologia dispõe. Nesse sentido, consideram-se os eventos de letramento que estão atrelados aos usos competentes que os sujeitos fazem da leitura e da escrita nas interações. Essa multimodalidade ou multimidialidade empregada aos usos da linguagem através do uso de várias linguagens constituem novos eventos de letramento.

Lê-se e escreye-se o tempo todo. Dedicamo-nos a atividades de leitura e escrita e respondemos às demandas sociais da contemporaneidade, utilizando-nos de aparatos tecnológicos para pesquisar, informar, interagir, enfim, produzir e partilhar saberes numa "heterogeneidade das práticas sociais" (ROJO, 2009, p. 102).

Como práticas sociais entendemos os saberes e vivências contextualizadas que cada sujeito experiencia ao longo da vida. Em conformidade com Xavier (2007), as práticas sociais são:

formas culturais pelas quais os indivíduos organizam, administram e realizam suas ações e atitudes esperadas em cada um dos diversos Eventos de Letramento existentes na sociedade. Essas ações são, ao longo do tempo, construídas conjuntamente pelos cidadãos comuns, e algumas delas passam a 
ser ritualizadas e oficializadas, posteriormente, pelas instituições que as retomam e exigem que os indivíduos as utilizem em momentos específicos da vida social. Os indivíduos, quando são expostos sociocomunicativamente a esses eventos, tendem a sedimentar usos de formas de fala ou escrita e, assim, absorve-os com certa naturalidade. (XAVIER, 2007, p. 142)

Nesse contexto, a tecnologia foi se tornando um bem necessário, embora ainda haja grande parte da população brasileira que desconheça ou não tenha a ela acesso, ou ainda a mobilize muito aquém de suas possibilidades - como seria o caso da escola, sobretudo as situadas nas regiões periféricas do país. Considerando o contexto educacional revelado em escolas públicas do Brasil, as novas práticas sociais de letramento digital não se realizam dada a inexistência dos recursos tecnológicos ou mesmo por sua precária apropriação.

As práticas de letramento permeiam a vida de todo sujeito em contextos sociais diversos, e essa multiplicidade de práticas e modos de significar permitem aos seus sujeitos um aprendizado que se redimensiona. Segundo Rojo (2009):

A multissemiose ou a multiplicidade de modos de significar que as possibilidades multimidiáticas e hipermidiáticas do texto eletrônico trazem para o ato de leitura: já não basta mais a leitura do texto verbal escrito - é preciso relacioná-lo com um conjunto de signos de outras modalidades de linguagem (imagem estática, imagem em movimento, música, fala) que o cercam, ou intercalam ou impregnam; esses textos multissemióticos extrapolam os limites dos ambientes digitais e invadiram também os impressos (jornais, revistas, livros didáticos). (ROJO, 2009, p. 105)

No contexto educacional, a tecnologia tem exercido um papel significativo, pois através dos computadores e da internet, tem-se a possibilidade hoje de interagir em tempo real com pessoas, buscar informações, divulgar conteúdos, construir conhecimentos, ser sujeito da própria aprendizagem. Esse universo trazido pelo avanço tecnológico passou a exigir usuários/consumidores cada vez mais exigentes quanto à qualidade dos produtos inventados e quanto à utilidade que foram sendo atreladas a esses equipamentos. Exemplo disso é o computador de mesa que começou a ser substituído pelos notebooks, os notebooks pelos celulares e tablets. Hoje vê-se uma busca pelo modelo mais leve, ágil, interativo.

Todos esses avanços deram origem ao que se chama de ciberespaços, produzindo interconexão mundial dos computadores. Nesse contexto que surge o hipertexto definido como um novo recurso no processo ensino e aprendizagem nas diversas áreas do conhecimento. Conforme Lévy, hipertexto "é um texto móvel, caleidoscópico, que apresenta suas facetas, gira, dobra-se e desdobra-se à vontade frente ao leitor" (LÉVY, 1999, p. 56). Essa versatilidade do 
hipertexto deslumbra e, por isso, envolve os jovens e prende sua atenção, levando-os a ler e escrever gêneros digitais, em especial nas redes sociais (Facebook, Twitter, Instagram etc.), ao mesmo tempo em que se tornam leitores de um texto que se abre para outros, interligados explicitamente por uma rede de conexões, que o tornam aparentemente infindável, marcado pela abertura e pela polifonia.

Diante disso, a escola deve permitir aos seus alunos práticas de letramento pela leitura e da escrita de gêneros presentes nas práticas sociais como o ciberespaço como condição para sua própria cidadania. Aí entram os desafios que novas configurações da linguagem apresentam e os saberes que podem ser desenvolvidos na escola frente aos recursos nela disponíveis.

\section{0 caráter de pesquisa participante}

A intervenção é resultado de uma pesquisa participante de caráter qualitativo, fundamentada no paradigma interpretativista, uma vez que assumiu o "compromisso com a interpretação das ações sociais e com os significados que as pessoas conferem a essas ações na vida social" (BORTONI-RICARDO, 2008, p. 32-34).

Todo o percurso investigativo e de intervenção durou um ano e quatro meses. Em 2014, na primeira etapa da pesquisa, dedicamo-nos a apresentar e desenvolver um projeto de leitura e escrita que culminaria na criação de um blog, para abrigar produções dos alunos e servir de espaço de interação e partilha de saberes entre alunos e professores. Toda a proposta visava a evidenciar a rentabilidade de usos do digital para o letramento dos alunos. As dificuldades então vivenciadas evidenciaram a pouca familiaridade dos docentes com os usos digitais e, assim, no primeiro semestre de 2015, desenvolvemos oficinas para os professores da escola-campo.

A pesquisa participante é "um instrumento científico, político e pedagógico de produção partilhada" (BRANDÃO, 2006, p. 31). É ainda "uma prática pessoal e coletiva de valor pedagógico, na medida em que sempre algo novo e essencial se aprende através de experiências práticas de diálogo e de reciprocidade na construção do conhecimento" (BRANDÃO, 2006, p. 31-32).

O corpus da pesquisa constitui-se de documentos diversos: uma entrevista com três professores-participantes; produções escritas dos alunos; áudios das oficinas (intervenção junto ao professor); print dos blogs criados na oficina da formação continuada. 
Os participantes da pesquisa foram, inicialmente, dois professores (das disciplinas de Língua Portuguesa e História), a gestora, a coordenadora do laboratório de informática e os dezoito alunos de uma turma de sétimo ano. Em seguida, aderiram à proposta três professores (das disciplinas de Arte, Matemática e Ética) e a coordenadora pedagógica. Os professores participantes têm entre 5 e 21 anos de experiência em sala de aula. Todos são licenciados e atendem ao quantitativo de 120 e 200 alunos por ano, distribuídos nas suas respectivas turmas/anos. Os participantes serão mencionados por pseudônimos, obedecendo à sugestão de um deles conforme a afinidade com educadores, artistas, escritores ou cientistas que admiram. Deste modo, serão assim identificados:

Quadro 1 - Pseudônimos: professores participantes

\begin{tabular}{l|l}
\hline Disciplina & Pseudônimo \\
\hline Língua Portuguesa & Cecília \\
\hline Matemática & Emmy \\
\hline Arte & Tarsila \\
\hline História & Cabral \\
\hline Ética & Mill \\
\hline Coordenadora de laboratório e estudos & Hellen \\
\hline Coordenadora pedagógica & Anne \\
\hline Gestora & Clarice \\
\hline
\end{tabular}

Fonte: dados da pesquisa.

Para a segunda etapa da intervenção, contamos com a colaboração voluntária de três membros externos, professores pesquisadores das temáticas "letramento digital" e "formação de professores". Dois destes são vinculados ao GESTO, e um mestrando pela Universidade Estadual de Campinas - UNICAMP. Os participantes serão referenciados ao longo das seções como formadores seguido de numerais $(1,2,3$ ou 4) que identificarão também a ordem das oficinas ministradas.

Todo o percurso investigativo e de intervenção foi estruturado em três etapas: i. visita à unidade escolar (aplicação de questionário aos alunos e entrevistas com os participantes (professores, coordenadores e gestora); ii. estudo, elaboração e análise da proposta de pesquisa participante; iii. intervenção em sala (foco no aluno); iv. intervenção junto aos professores com oficinas de formação teórico-práticas sobre letramento digital (foco no professor). 


\section{Resultados}

O recorte dos resultados apresentados aqui funda-se, basicamente, na semiótica e apresenta os dados coletados (entrevista com professores, produção textual dos alunos e oficina com os professores) considerando os enunciados que permitirão aos nossos interlocutores compreender as principais questões discutidas e analisadas ao longo do percurso de pesquisa e intervenção, mantendo fidedignidade aos enunciados produzidos pelos participantes.

\subsection{Interações e transformações em processo na escola}

Considerando narrativa como mudança de estado do sujeito (GREIMAS e COURTÈS, 2008), o que se narra aqui são as transformações - ainda que frágeis do ponto de vista das possibilidades - do professor mediante o desenvolvimento da pesquisa participante.

$\mathrm{Na}$ perspectiva de uma narrativa elementar, num primeiro momento, o professor se encontraria em disjunção com o digital, concebido como ferramenta de ensino. Tal disjunção se daria por questões diversas (não saber usar programas, não ter familiaridade mesmo com o emprego de e-mails, insuficiência de equipamentos na escola para atender adequadamente ao número de alunos na sala, problemas quanto à disponibilidade do laboratório para uso dos docentes etc.), conforme nos confirmam os dados mobilizados na pesquisa. A transformação se daria pela intromissão da pesquisadora, atuando como destinador que, sem necessariamente transformar drasticamente as condições que dificultavam a conjunção, age no sentido de levar o professor a querer mudar aspectos da sua prática, a arriscar-se em um projeto para o qual acreditava ser incapaz ou por ser indesejado, na medida em que também adquire novos saberes (aprende a usar e-mail, atua diretamente nos planejamentos para os usos do blog, participa ativamente da construção do blog, envolve-se com a sua continuidade, descobre recursos que podem contribuir para o ensino etc.). Os "enunciados de estado" assim como os "enunciados de fazer" configuram-se dois tipos de enunciados elementares da sintaxe narrativa. Os enunciados de estado são os que estabelecem uma relação de junção (disjunção e conjunção) (FIORIN, 2008, p. 28).

Por disjunção, em semiótica narrativa, entende-se "paradigmaticamente, um dos dois termos (o outro é conjunção) da categoria junção (que se define, no plano sintagmático, como a relação entre o sujeito e o objeto, isto é, como a função constitutiva dos enunciados de estado)" (GREIMAS, 2008, p. 149). Considerando, então, essa relação entre o sujeito e o objeto, 
analisaremos como a junção, seja disjuntiva ou conjuntiva, vai se manifestando nos textos e, assim, construindo os sentidos através do que discursivizam na sua relação com o digital.

Para a semiótica discursiva, a figura do manipulador é a de um sujeito que faz fazer, que age sobre um outro mediante diferentes estratégias de "manipulação": intimidação ou provocação, que fazem com que o sujeito manipulado - denominado pela teoria como destinatário - seja levado a fazer por um dever fazer; sedução ou tentação, quando o destinatário é levado a fazer um por querer fazer. A isso se acrescem outras transformações, como a da passagem do medo à esperança, na medida em que o que relatam os docentes participantes diz respeito ao estado passional: do medo de usar o computador à esperança de construção de possibilidades, na medida em que se familiarizaram com certos usos. Ambas são paixões que remetem, do ponto de vista da aspectualização, ao não começado (FIORIN, 2007), mas a primeira é incapacitante, disfórica, enquanto a segunda abre-se ao devir, eufórica.

Como uma teoria da significação, a semiótica considera que regem as interações dos sujeitos dimensões que extrapolam elementos puramente cognitivos, considerando, assim, também, a dimensão do passional e do afeto. Não há apenas razão e cognição agindo sobre os sujeitos que negociam valores, perspectivas, compromissos. O medo, enunciado por todos os participantes, age sobre os sujeitos no sentido de um não poder fazer, estacionando-os num estágio anterior à ação pretendida. Nesse sentido, foi necessário desmitificar a inacessibilidade do digital para que os docentes pudessem desapegar-se do medo, pondo-se em prontidão para o fazer, a performance.

Manipulando inicialmente os professores por sedução (reuniões, eventos, aulas), agimos no sentido de fazê-los querer, o que produziria a passagem da disjunção à conjunção. A noção de estado, porém, não pode ser concebida senão como um processo, condizente com a própria definição de letramento digital. Além disso, há mais que se considerar nessa narrativa, na medida em que nem tudo é assimetria de papéis actanciais (destinador/destinatário). Temos então um segundo momento na escola, quando os professores passam a vivenciar o que a sociossemiótica, ao problematizar a noção de interação da semiótica discursiva standard, traduz como ajustamento (LANDOWSKI, 2014). É nesse momento em que se inicia propriamente a colaboração e a aprendizagem conjunta visando às práticas educativas (planejamento e construção coletiva do blog operada pelos diferentes sujeitos: coordenadora, professores de Língua Portuguesa, de Arte, de Matemática e a pesquisadora). 
Nesse sentido, trazemos o percurso dos professores participantes que aderiram à intervenção pedagógica que tematizou o digital partindo de um não saber que avançou para um estado de saber adquirido quando passaram a reconhecer o blog como uma estratégia de ensino. As postagens no blog comprovam esse saber adquirido, embora evidenciem também que as transformações indicam ainda um longo caminho a percorrer, o que nos levará à etapa seguinte da intervenção (oficinas de letramento digital com os professores).

Deve-se levar em conta ainda que os textos não são sempre compostos de narrativas mínimas, mas "são narrativas complexas, em que uma série de enunciados de fazer e de ser (de estado) estão organizados hierarquicamente," e "estruturam-se numa sequência canônica compreendida em quatro fases: manipulação, competência, performance e sanção" (FIORIN, 2008, p. 29).

No intuito de explicitar cada fase da sequência narrativa canônica, iniciaremos um breve esboço acerca da manipulação, que não tem na teoria o sentido negativo do termo no seu uso comum. Segundo Greimas, a manipulação consiste numa "ação do homem sobre outros homens, visando fazê-los executar um programa dado: no primeiro caso, trata-se de um 'fazerser', no segundo, de um 'fazer-fazer'” (GREIMAS, 2008, p. 300).

No contexto da intervenção pedagógica, enquanto pesquisadora, fomos assumindo o papel de destinadora (manipuladora) com a perspectiva de seduzir os professores, inicialmente, a colaborarem a pesquisa participante e aderirem ao projeto apresentado. Nesse sentido, utilizamos a manipulação por sedução como forma de ação junto aos professores propondo uma experiência com o digital no sentido de adotá-lo como estratégia de ensino.

O primeiro momento de manipulação se deu pelo esforço de, enquanto destinadores, ganhar a confiança dos participantes-professores, fazendo-os crer na proposta de intervenção pedagógica. O outro momento se deu quando os professores se tornaram de fato participantes da intervenção, levando-os à construção do blog, ou seja, cada sujeito passou a colaborar com o processo.

No que diz respeito à fase da competência, "o sujeito que vai realizar a transformação central da narrativa é dotado de um saber e/ou poder fazer" (FIORIN, 2008, p. 30). Para a performance pretendida, fase seguinte do percurso narrativo canônico, não basta, portanto, apenas o querer (construído pela manipulação por sedução), mas também o saber (que, se não foi adquirido/produzido em outros momentos da formação docente, deve ser doado pelo destinador, conforme previsto na sintaxe narrativa). Esse percurso nos levaria (pesquisadora e 
participantes - professores e alunos) à performance que consiste numa "mudança de um estado a outro" (FIORIN, 2008, p. 31). No caso da intervenção, os participantes passariam de um não saber/não poder- fazer a um saber fazer colaborativo.

\subsubsection{O digital na escola-campo: um laboratório; muitas interdições}

Considerando que a escola possui um laboratório e motivados pelas questões norteadoras da pesquisa e questões semiestruturadas, entrevistamos três professores (Cecília, Cabral e Clarice). Todas as questões geraram dados relevantes, porém, analisaremos abaixo, apenas cinco questionamentos que, de certa forma, resumem as demais e nos permitem olhar o contexto escolar e compreender as suas peculiaridades, bem como as perspectivas dos professores.

A primeira questão consistiu em considerar o que os professores e coordenadora pensam de aulas com computador. Cecília, a professora de Língua Portuguesa, bem à vontade com a entrevista e demonstrando disponibilidade e interesse para o que propomos nesta pesquisa participante, logo respondeu:

\section{Entrevista 1}

É legal, mas a gente usa pouco. Dificilmente eu uso. Pois, até eu mesma tenho dificuldades em usar. Muitas vezes, quando eu vou usar, usar um filme ou que seja uma coisa de outro tipo, eu peço alguém para me ajudar. Peço alguém que trabalha no Laboratório de Informática. (Cecília)

A fala da professora Cecília expressa diretamente as razões para usar de modo restrito o laboratório da escola. Como na passagem negritada, as restrições advêm do próprio desconhecimento no manejo de tecnologias, não apenas restritas ao digital. Ao mesmo tempo, essa limitação não a exime de planejar aulas utilizando o laboratório como espaço de aprendizagem e os computadores como estratégia e ensino, para isso contando com o apoio de um colega: "Peço alguém que trabalha no Laboratório de Informática". Vai evidenciando, portanto, a pouca familiaridade com os recursos tecnológicos e a necessidade de ampliar seus saberes.

Assim, vamos percebendo, ao longo da entrevista que tanto há uma relação disjunta por parte do professor para com o digital, quando consideramos o discurso de Cecília: "É legal, mas a gente usa pouco. Dificilmente eu uso.”, quanto da escola ao analisar o que diz Cabral: "Nós tivemos muitos problemas com isso (o uso de tecnologias digitais, o celular)". 
A maneira como cada sujeito percebe um dado objeto o conduz a uma percepção do sentido. Assim, quando a proposta de intervenção foi sendo construída, deu-se início a um processo de passagem de um não-saber a um saber. Considerando o que Cecília diz: "Muitas vezes, quando eu vou usar, usar um filme ou que seja uma coisa de outro tipo, eu peço alguém para me ajudar. Peço alguém que trabalha no Laboratório de Informática”, o laboratório era pretexto para práticas outras que não de uso do computador como estratégia para ler e escrever utilizando-se de gêneros hipermidiáticos. Após a intervenção pedagógica, os professores participantes iniciaram um fazer conjunto a partir de uma aprendizagem colaborativa acerca dos usos da tecnologia digital, entrando assim em conjunção com o digital, ainda que elementar e incipiente, que aponta para um processo a ser desenvolvido:

$\mathrm{Na}$ sequência, os professores-participantes foram perguntados se tinham alguma formação voltada para o uso de computadores no ensino e quais são as dificuldades encontradas no que diz respeito ao uso dos computadores para o ensino.

Entrevista 2

A dificuldade que encontramos é a quantidade de computadores para a quantidade de alunos que temos. Ou quando nós usamos o laboratório, usamos o Datashow para que eles acompanhem o passo a passo das atividades, dos comandos. (Clarice)

Além disso, o discurso acima apresenta uma relação de conflito entre saber e poder: o sujeito sabe usar, mas não pode, é impossibilitado por situações adversas (incompatibilidade de horários, equipamentos insuficientes etc.). A fala da coordenadora sobre o uso do Datashow"usamos o Data show para que eles acompanhem o passo a passo das atividades, dos comandos" - provocou-nos algumas inquietações sobre o uso da tecnologia como estratégia de ensino e suporte de aprendizagem.

Perguntamos ainda a cada um deles: O laboratório é um espaço que considera para ministrar suas aulas?

\section{Entrevista 3}

Sim, desde que o professor tivesse uma formação voltada para isso. Ajudaria bastante. Também acho que um laboratório só, é pouco. Hoje mesmo era para eu ter trazido os alunos para cá (laboratório), mas já não deu. Seria nesse terceiro horário e no quarto, mas disseram que estava ocupado. Às vezes a gente programa uma aula e acaba não acontecendo. Às vezes agenda, mas também tem os próprios estudos que estão acontecendo aqui no laboratório, pela manhã e à tarde. Às vezes, choca com as aulas. Mas pensando num cronograma, talvez melhore. (Cecília) 
A professora Cecília aborda questões importantes para que trabalho docente seja eficiente no que diz respeito ao uso das tecnologias digitais na escola: "Sim, desde que o professor tivesse uma formação voltada para isso. Ajudaria bastante.”. As tecnologias foram sendo adotadas no âmbito das escolas e esperou-se que a sua utilização fosse um fazer já próprio do professor. Porém, não se considerou que o professor não tivesse desenvolvido competências para o manuseio dos equipamentos, tampouco que a internet fosse um espaço não usual para professores de escolas públicas, em destaque aqui, os professores do Sistema Municipal de Ensino no norte do Tocantins.

Outras questões enunciadas pela professora Cecília tornam visíveis a sua inquietação quanto à adoção do laboratório como espaço de aprendizagem: “Também acho que um laboratório só, é pouco. Hoje mesmo era para eu ter trazido os alunos para cá (laboratório), mas já não deu.”. O querer fazer da professora tropeça no poder fazer impossibilitado pela falta de mais espaços informatizados na escola. Numa escola que atende mais de 896 alunos, de fato um laboratório limita o trabalho dos docentes, mesmo quando há uma programação prévia.

Considerando o discurso dos professores em cada enunciado aqui apresentado, constatamos que, além desses empecilhos, há ainda a diversidade de ações desenvolvidas no âmbito do laboratório (atendimento à comunidade, cursos de formação de professores, atendimento aos alunos no contra turno para pesquisas escolares, aulas no turno de regência planejadas pelos docentes).

Na sequência, questionamos: Como você, professor, avalia a relação dos alunos com a tecnologia? E o uso que fazem das redes sociais?

\section{Entrevista 4}

Os alunos usam. Usam o WhatsApp que eles conhecem muito bem. Já o Facebook, nem todos. Eu acho que é bom. Mas quando querem usar o WhatsApp em sala de aula, atrapalha. Querem ficar acessando. Mas aqui na escola tem uma regra, nem o professor e nem o aluno podem usar o celular em sala. (Cecília)

A fala de Cecília expõe duas situações que vivencia na escola quanto ao uso do digital: a primeira é o fato de o WhatsApp em sala de aula atrapalhar o processo ensino e aprendizagem e, a segunda, é que nem o aluno e nem os professores podem utilizar o celular em sala. A escola coíbe a relação já construída pelo sujeito fora da escola com o objeto celular, ou seja, o sujeito é impedido de usar o celular em função de normas estabelecidas pela instituição. O desejável (usar o celular na escola) então passa a ser objeto de proibição e punição. Assim, fica evidente que a tecnologia existente na escola é reprimida quando parece uma possibilidade que pode ser 
transformada em aliada aos processos ensino e aprendizagem. A exemplo disso, em Conceição do Araguaia, uma professora, mestranda pelo PROFLETRAS, utiliza o celular como suporte nas aulas de inglês como dicionário, áudio e vídeo (relato de experiência ${ }^{1}$ ).

Assim como noutro tempo houve e talvez ainda haja o livro proibido, vemos isso se repetir com o uso das tecnologias na escola. Cecília diz: "Mas aqui na escola tem uma regra, nem o professor e nem o aluno podem usar o celular em sala", e também a fala do professor de História: "Tivemos até problemas já, de aluno com o celular e tivemos que tomar [recolher]", vemos que é possível um fazer no sentido de utilizar esse interesse efervescente que os alunos demonstram pelas tecnologias em prol da aprendizagem, da construção de novos conhecimentos. Interessante que mesmo o docente é impedido de usar o aparelho, o que denota sua noção de entrave, perigo, jamais como aliado de ambos.

Suscitamos entre os participantes o desejo de implementar, no âmbito da pesquisa participante, a criação de um blog para que os alunos possam ler e escrever textos discursivos no ambiente virtual e, assim, atender a proposta curricular de maneira significativa. Diante disso, buscamos verificar se os professores participantes já haviam pensado em adotar um blog como estratégia para levar o aluno ler e escrever.

Entrevista 5

Não, nunca pensei. Acho até que pode ser interessante (Cecília).

Entrevista 6

Não. Até o momento não. Nunca trabalhei com isso, mas acho que a gente pode tentar. Não estou a par disso, mas acho que vale a pena tentar (Cabral).

Entrevista 7

Olha, até o ano passado enquanto você não havia chegado com a ideia, não. Mas a partir do momento que chegou (pesquisadora) com essa ideia de criarmos o blog começando principalmente com os alunos do $9^{\circ}$ ano, eu comprei essa ideia. Eu gostaria e quero que continue esse projeto na escola (Clarice).

Diante dos relatos supracitados, o primeiro sentimento é de inquietude, pois revelam que os gêneros hipermidiáticos não permeiam as práticas de leitura e escrita na escola-campo. Revela ainda que os gêneros multimidiáticos são desconhecidos pelos professores, porém, demonstram interesse em aprendê-los. As passagens acima constituem o momento da sedução,

\footnotetext{
${ }^{1}$ SILVA, Robervânia de Lima Sá. Letramento Digital: o ensino de Língua Inglesa e o aparelho celular. Revista Linha Mestra. Ano VII. N.24 (Jan. Jul.2014).
} 
a que nos reportamos há pouco: os docentes passam então a querer, o que fará toda a diferença para um projeto que precisa ser construído colaborativamente.

Iniciamos o processo de manipulação, à princípio seduzindo a professora Cecília apresentando a ela as possibilidades do blog quando utilizado como estratégia de ensino. Para isso, interrompemos a entrevista e visitamos alguns blogs e sites educacionais ${ }^{2}$ e, assim, a professora foi modalizada pelo fazer-crer vislumbrando o saber-fazer para que sua prática seja modificada.

Dolz e Schneuwly (2010) definem o "gênero como instrumento" e analisam o que propõe Rabardel sobre o texto ser um instrumento mediador: fora do sujeito ("materializando, por sua própria forma, as operações que tornam possíveis os fins aos quais o instrumento é destinado"), e do sujeito ("há os esquemas de utilização do objeto que articulam suas possibilidades às situações de ação (por exemplo, tarefas a resolver)"), ancorados em considerações psicológicas, classificando-o como artefato material ou simbólico e o do sujeito. "O instrumento, para se tornar mediador, para se tornar transformador da atividade, precisa ser apropriado pelo sujeito; ele não é eficaz senão à medida que se constroem, por parte do sujeito, os esquemas de sua utilização" (DOLZ E SECHNEUWLY, 2010, p. 21-22).

Em consonância com a concepção de gênero de Dolz e Schneuwly, cremos que o blog pode constituir-se um instrumento mediador para o processo ensino e aprendizagem dos alunos, uma vez que percebemos o interesse dos adolescentes, de um modo geral, pelo uso das tecnologias digitais. Nesse sentido, o projeto temático configura-se como uma oportunidade de garantir uma prática da escola redimensionada pela construção do blog e que garantirá um trabalho interdisciplinar.

Enfim, a partir dos relatos dos professores-participantes, reforçou-nos a crença de que o ensino não pode se dar sem considerar o contexto dos alunos. O esforço de a escola promover um ensino voltado para a promoção dos seus sujeitos ainda não considera as tecnologias digitais como instrumento de ensino, nem os textos multissemióticos, os gêneros hipermidiáticos, como gêneros discursivos híbridos que convocam a novos letramentos a serem vivenciados na escola. O fato é que ainda não conseguimos integrar os conhecimentos multimidiáticos aos curriculares tradicionais (LEMKE, 2010), e precisamos avançar nesse sentido, pois as ferramentas colaborativas têm se tornado indispensáveis nas novas relações nas sociedades. É

\footnotetext{
2 Acessamos os blogs: http://revistaescola.abril.com.br/blogs/; http://memoriasericadecassia.blogspot.com.br/; http://www.museudalinguaportuguesa.org.br/; http://revistalingua.com.br/textos/64/artigo249031-1.asp.
} 
imprescindível, portanto, que se construa continuamente um diálogo entre todos os sujeitos da escola (gestor, coordenador, professores, alunos e pais) no intuito de materializar as práticas de interação social.

\subsection{Olhares dos discentes sobre o digital e primeiras produções do blog}

Trazemos aqui análise dos textos escritos dos alunos que tematizaram o uso das tecnologias digitais, bem como as postagens no blog "Gênios do futuro". Consideramos o modo como cada sujeito-aluno discursivizou a sua relação com o digital e refletimos a sua utilização em benefício do ensino-aprendizagem na escola-campo. A ideia era explorar os percursos temáticos e figurativos presentes nos textos dos alunos a partir dos textos por eles produzidos em sala e as primeiras postagens blog. Os textos escritos pelos alunos serão enumerados obedecendo a sequência numérica na ordem crescente e seguido de nomes fictícios.

\subsubsection{A construção temática e figurativa nos textos dos alunos e o digital}

O nível discursivo instrumentalizará a presente análise que envolve os processos de tematização e figurativização sob a perspectiva do que a semiótica discursiva compreende como semântica discursiva. A semântica do nível discursivo envolve dois processos: tematização e figurativização. A tematização é concebida como procedimento "sob a forma de tema, pelos programas e percurso narrativo, abrindo assim o caminho à sua eventual figurativização" (GREIMAS, 2008, p. 496), sendo os temas categorias abstratas que organizam as experiências do mundo natural, como saudade, trabalho, tristeza etc.

Ao longo do texto, o sujeito da enunciação constrói o percurso discursivo através de recorrências, definidas em termos semióticos como isotopias - também inerentes à figurativização - e que evidenciam que os temas são constituídos isoladamente, mas numa espécie de rede que lhes confirma uma orientação de sentido e lhes confere coerência semântica. A isotopia diz respeito à interatividade construída no decorrer de uma cadeia sintagmática que assegura ao "discurso-enunciado a homogeneidade" (GREIMAS, 2008, p. 276). Assim, o tema do sucesso pode ser reiterado por outros temas como o da riqueza, do reconhecimento social, da premiação etc., concretizado sob diferentes figuras: roupas de grife, carros de luxo, aplausos, fãs etc. Na articulação entre temas e figuras edifica-se a dimensão ideológica do texto.

Interessou-nos considerar a maneira como cada sujeito-colaborador da intervenção pedagógica discursiviza a sua relação com o digital. 


\subsubsection{O sujeito-aluno e o uso das tecnologias digitais dentro e fora da escola: textos escolares}

Serão apresentados fragmentos dos textos dissertativos-argumentativos frutos de aulas interdisciplinares. A professora de Língua Portuguesa propôs a produção de um texto dissertativo-argumentativo tematizando a seguinte questão: Como você usa a tecnologia? A ideia foi incitar os dezesseis alunos presentes na aula a refletirem enquanto sujeito social, como se viam diante do avanço tecnológico.

Analisando as produções escritas, pudemos identificar os papéis temáticos que os sujeitos-alunos foram construindo ao conceberem o internauta ${ }^{3}$ como um sujeito que sempre está em risco, pois transitaria o tempo todo entre o bem e o mal, tematizando a incerteza e as inseguranças diante do virtual. Parece que o internauta está sempre sujeito ao abuso, ao perigo. Em contrapartida, há outros discursos construídos pelos sujeitos-alunos que estão carregados de certezas, mas que se entusiasmam significativamente, deslumbrando-se diante das promessas da tecnologia. Discutiremos aqui como os sujeitos-alunos participam ou são modalizados pela tecnologia disponível na escola e também fora dela através do que enunciam nos textos escritos.

Os discursos enunciados pelos alunos vão construindo ideias que mostram diferentes perspectivas sobre os usos do digital:

... outros usam o computador e isso parece estranho, pois a partir do momento que a pessoa deixa de falar para editar, ela pode muito bem parar de dizer a verdade para mentir. Por isso é complicado usar a internet, o celular ou computador para simplesmente fazer o mal. (ROMEU, 2014)

No recorte acima, Romeu tematiza a tecnologia como algo perigoso, pois atribui ao objeto computador a responsabilidade mentir ou falar a verdade. Essa percepção figura um sujeito que oferece resistência ao digital, pois mentir ou dizer a verdade não são possibilidades colocadas apenas para quem está diante de um computador, mas depende daquele que o utiliza como ferramenta. De certo modo, pensamos que a fala denuncia a pouca familiaridade, reproduzindo os mitos que o cercam mais do que as experiências pessoais. O mesmo tema da maldade no digital aparece também nos textos a de João e Hamlet e apontam mais para o que supostamente pensa que o professor quer ouvir, diante da vocação moralizadora da escola:

\footnotetext{
${ }^{3}$ Usuário interativo da internet.
} 
A tecnologia faz o bem como também faz o mal. Eu gosto sim de mexer no celular, computador etc. Mas também não uso para fazer o mal, uso para me comunicar com amigos distantes ou familiares. Eu me vejo por dentro da tecnologia e mexer de vez enquanto não faz mal para ninguém. (João, 2014)

No fragmento supracitado, o aluno reafirma os valores bem e mal como autoridade da tecnologia figurativizada pelo objeto computador. Conceber um objeto como destinador do comportamento humano parece ser resultado da pouca familiaridade com o objeto, ou, arriscamos dizer, que essa compreensão está vinculada ao que o sujeito ouve dizer a respeito da tecnologia e não um saber fruto da sua própria vivência.

O raciocínio de Romeu continua na mesma direção maniqueísta:

Quando se trata de ajudar alguém ou se comunicar é outra coisa. Até concordo e uso porque a internet e útil e bom, pois com ela podemos ver o mundo de outra maneira, se tornando interessante estudar. No meu dia-a-dia costumo sim usar a internet para jogos, pesquisar e falar on-line com meus amigos, então para mim quando se trata de coisas boas concordo com as novas tecnologias, mas quando não, discordo totalmente. (ROMEU, 2014)

A esse enunciado se soma outro que aponta para os malefícios trazidos pela tecnologia:

Celular é bom para se comunicar com pessoas lá fora. Pessoas que estão distantes. Eu acho que se numa casa todos tivessem computadores seria muito chato, pois ia ser muito difícil para muitos dar atenção (HAMLET, 2014).

Os enunciados chamam a atenção para a temática do afeto que perderia em qualidade em função das interações através de recursos multimidiáticos, atingindo os próximos (familiares, amigos) e os distantes (namorado/a). As produções denunciam resistências, comuns no discurso de sujeitos mais velhos e não nativos digitais.

A tecnologia tematizada discursivamente nos textos dos alunos parece não ser pensada ainda como possibilidade de aprendizagem. O conceito de aprendizagem que ancora as práticas de uso do digital na escola é o de aprendizagem colaborativa que "acorre mediada por situações educacionais em que duas ou mais pessoas dispõem a aprender algo em parceria" (LIMA; VIEIRA, 2007, p. 3). A aprendizagem assim concebida implica o fazer conjunto e que nem sempre exige a presença do professor e os sujeitos-alunos são capazes de interagir mediados por múltiplos objetos: celular, computador, livros.

A tecnologia parece tematizar a existência de diferentes gerações numa mesma época. Existem os sujeitos que nasceram antes da tecnologia e os que nasceram na tecnologia - são os 
nativos digitais, o que a constitui um divisor de águas e marca uma ruptura com as formas de vida, com as maneiras de interagir socialmente.

\section{Texto Escrito 5}

Hoje em dia é muito difícil para algumas pessoas que não estudaram no passado, porque no passado era mais difícil as pessoas terem computadores, celulares, relógios, tablet. Os computadores são bem utilizados hoje em dia. Muitas pessoas queriam que no lugar de livros fosse tablete e que cada pessoa tivesse um computador. (Hamlet, 2014)

Texto Escrito 6

A tecnologia tem feito várias mudanças, que estão mudando o nosso comportamento. As crianças de antigamente não tinham acesso à tecnologia, mas agora as crianças já nascem com a tecnologia. (Noel, 2014)

O sujeito-aluno Hamlet tematiza a ruptura que entendemos atravessar os sujeitos contemporâneos nascidos no processo de desenvolvimento da tecnologia e que passou a exigir novos saberes de seus usuários. Percebemos nesse texto que o enunciador realiza uma trajetória que retoma o tempo dos seus avós quando utilizavam o sol como relógio, uma prática comum de homens do campo. Supomos que esse saber foi suscitado pela aula de História que mobilizou conhecimentos da evolução tecnológica ao longo dos tempos.

O texto aborda ainda os nativos digitais: "As crianças de antigamente não tinham acesso à tecnologia, mas agora as crianças já nascem com a tecnologia” (Noel, 2014). São os letrados digitalmente que vivem em conjunção "naturalmente" com a tecnologia e utilizam-se das suas potencialidades para poderem fazer das suas práticas cotidianas (estudar e interagir), atividades otimizadas pela tecnologia.

No texto a seguir, o aluno reconhece-se como sujeito letrado virtualmente quando afirma ser sujeito participante do mundo tecnológico através do uso de mídias digitais.

\section{Texto Escrito 7}

Hoje a tecnologia está na vida de qualquer um. Para tudo que a pessoa vai fazer tem a tecnologia, principalmente, os jovens que ficam nas redes sociais Facebook, WhatsApp, Instagram, Chat. (Maria, 2014).

A tecnologia digital é tematizada nos textos acima como sinônima de acesso ao conhecimento e como espaço de novas relações através das redes sociais. Surgem aí termos específicos desse universo - WhatsApp, Facebook, internet - e expressões como "está conectada a uma só ligação". 
Considerando o que foi apresentado até aqui com relação à concepção e usos da tecnologia digital pelos sujeitos-alunos-participantes, percebemos que o olhar do aluno é altamente atravessado pelas crenças que o distanciariam do digital (malefícios, perigos), bem como a sua redução a esferas do entretenimento, resguardando o lugar da aprendizagem aos livros. Assim, a despeito do laboratório e de seu uso eventual na escola, a lógica ainda é grafocêntrica, isto é, centrada essencialmente no verbal, não modificada pelos usos individuais fora da escola conferidos pela própria situação socioeconômica dos alunos.

\subsubsection{Blog: relatos de uma experiência pedagógica}

Neste tópico, apresentaremos alguns registros do diário de campo que ilustram as dificuldades e frustrações manifestas durante o processo de criação e implementação do blog "Gênios do futuro". Além disso, serão apresentadas duas postagens que comprovam a adesão dos alunos e dos professores da escola-campo.

Depoimento 1

Foi fácil criar o blog. Criei rapidinho. Mas na hora de inserir os textos percebi que só aparecia no perfil e que algo estava errado. (Hellen, 2015)

No discurso supracitado, a docente Hellen tematiza as dificuldades e revela um nãosaber a respeito do ambiente virtual que dificulta o saber-fazer na prática pedagógica, reiterando a necessidade de formação nessa direção. Constatamos que a utilização pelos usuários é fácil, mas a manutenção pelo gestor do ambiente requer saberes técnicos mais sofisticados.

Fizemos três tentativas de levar os alunos-participantes para o laboratório de informática objetivando abrir as contas gmail, condição para o acesso ao blog, porém, em virtude da falta de internet, não conseguimos realizar conforme planejado. Isso gerou insatisfação nos alunos e angústias em nós, professores. Os alunos aspiravam visualizar o espaço que planejamos juntos e nós, professores, estávamos desejosos de colocar os alunos em contato com o blog já nomeado "Gênios do Futuro"."

Além das muitas dificuldades devido à infraestrutura inadequada do laboratório, tivemos ainda a falta dos alunos em virtude de outras atividades (jogos interclasse, ensaios para apresentações de atividades escolares, entre outras situações), o que não tirou a motivação dos participantes da pesquisa. Assim, foram cerca de 6 idas ao laboratório sem sucesso. Num desses

\footnotetext{
4 Blog criado em parceria com a professora Cecília e Hellen disponível no endereço: http://geniosdofuturomariadelourdes.blogspot.com.br/
} 
momentos, no dia 13 de maio do ano 2015, tínhamos planejado levar os alunos para a aula de criação do blog no laboratório de informática, porém, novamente estava sem internet. Propus retornar para a sala e trocar saberes com os alunos sobre o blog. Esse momento foi importante, embora imprevisto, pois pudemos verificar o que sabiam sobre o blog. Nesse diálogo, referiramse ao Blog do Théo, produzido por personagem da novela da Rede Globo "Império" que protagonizava um repórter dedicado a registrar situações constrangedoras vividas pelas personagens do folhetim caracterizadas como personalidades.

Discutimos a postura de quem escreve e os tipos de leitor desse tipo de gênero. Uma aluna classificou o Théo como repórter interativo, fato que permitiu uma rica reflexão em torno do termo "interação". Ao fundo da sala, ecoou uma voz questionando:

\section{Depoimento 2}

Quero acessar logo o nosso blog [Gênios do Futuro]. (MOGLI, 2015)

Foi motivadora essa interrupção, pois demonstrou a expectativa dos alunos diante da possibilidade de criar um ambiente virtual para que eles pudessem aprender e interagir. Em princípio, ficou combinado, mediante sugestão dos alunos, que fossem registradas a rotina da sala pelos seis alunos que possuem celular com câmera. O objetivo era socializar o dia-a-dia que vivenciam.

O início foi difícil para todos, alunos e professores e a pesquisa participante foi sendo redimensionada ao passo que íamos construindo juntos saberes e mudando concepções sobre o que parece fácil ou difícil no uso do digital como estratégia educacional. Nesse processo, fomos ensinando e aprendendo uns aos outros e, pelo fato de ser uma pesquisa participante, tive a oportunidade de não apenas ser um sujeito que observa, mas que atua e contribui, ensina e aprende.

Os alunos demonstraram muita dificuldade no manuseio do computador. Não conheciam as ferramentas e seguimos com mais cautela, descrevendo cada ferramenta do computador e do e-mail. Os alunos foram se familiarizando e noutro momento uns já ajudavam aos outros. O fazer conjunto deixou de ser apenas uma prática entre pesquisadora e os professores-participantes e passou a ser uma prática entre todos os sujeitos desse processo de intervenção pedagógica (pesquisadora-professores-alunos). Enfim, foi nessa troca recíproca de saberes que fomos nos ressignificando assim como o fazer pedagógico. 
A partir do que íamos experienciando no fazer com o blog, fomos percebendo a disjunção dos sujeitos alunos com o objeto computador. As percepções iniciais obtidas através dos textos escritos de certo modo escondiam esse afastamento e, ao se sentarem para manusear o computador, pudemos perceber mais de perto a falta de conhecimentos elementares como o do manuseio do mouse, a dificuldade para localizar os links, a prática de escrever no caderno para depois digitar.

Registramos dentre tantos, o sentimento da professora Helen, manifestado nesse percurso:

\section{Depoimento 3}

Professora, estou empolgada com o blog. Estou estudando no Google e vi que podemos colocar fotos e vídeos das nossas atividades. (Hellen, 2015).

Assim pudemos agilizar o processo e começamos a navegar conhecendo alguns blogs, num breve passeio pelos ambientes, fomos analisando a composição de cada um, os links e a diversidade de temáticas existentes. Ao final da aula, perguntamos como os sujeitos-alunos haviam idealizado o blog "Gênios do Futuro", o que gostariam de postar, inicialmente. Tomados pela euforia, disseram que queriam ver a sua cidade, discutir o meio ambiente, denunciar questões sociais, postar fotos da turma, postar vídeos com músicas que gostam. Os professores se comprometeram em atendê-los.

Toda essa trajetória nos trouxe, então, para o propósito maior da pesquisa participante, o blog "Gênios do Futuro".

Figura 1 - Leiaute do blog "Gênios do Futuro"

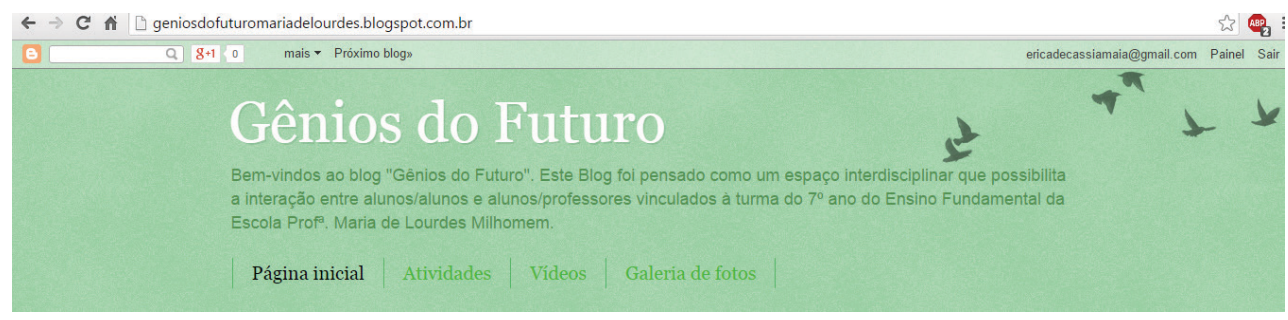

Fonte: dados da pesquisa.

Considerando todo o processo de construção e as experiências de uso do $b l o g$, este não necessariamente alterou práticas escolares tradicionais. As atividades postadas pelos professores-participantes voltaram-se para temas escolares (festa junina, discussões sobre valores morais), mas o aluno teria possibilidade de consultar textos e, embora a aula de Arte 
tematizasse ética e moral, os alunos poderiam observar as postagens dos colegas e redimensionar as suas, efetivamente usando o suporte para diálogo com o outro. Tratava-se das primeiras experiências e acreditamos que o processo iniciado possa dar origem a práticas mais significativas de leitura e escrita.

\subsection{As transformações dos professores-participantes: do querer-fazer ao saber-fazer 5}

Como etapa final da pesquisa ora apresentada, realizamos uma segunda intervenção, desta vez, junto aos professores participantes da pesquisa. Objetivamos empoderar os professores-participantes quanto ao uso das tecnologias digitais como estratégia de ensino e aprendizagem. Foram realizadas quatro oficinas tematizando: "Concepções: letramento digital, multiletramentos, escrita colaborativa, gênero hipermidiático, e cibercultura"; pesquisando na internet - o Youtube e Observatórios de língua e leitura, literatura etc., e outros sites educacionais como fontes de pesquisa", "Correio eletrônico e a escrita colaborativa utilizando o Google Drive", e o "O blog e as redes sociais". Analisamos os discursos dos professoresparticipantes ancorados nas categorias do nível narrativo, uma vez que a semiótica exerce nesta pesquisa, o caráter de teoria sujeito (GREIMAS; FONTANILLE, 1984; SILVA; REIS, 2014, p. 44). Os discursos dos participantes foram registrados em áudio durante as oficinas e transcritos na sequência, fidedignamente. Ao final das oficinas, foi notável o processo de ajustamento dos professores às atividades propostas, ilustrando assim, às transformações modais (querer-fazer, saber-fazer e poder-fazer) vivenciadas pelos actantes.

Convém destacar que os professores-participantes possuíam conhecimentos elementares no que diz respeito ao uso das tecnologias digitais e esse fato dificultou a ação pretendida. Em contrapartida, a não utilização das interfaces disponíveis na hipermídia estabeleceu a troca, um fazer conjunto e colaborativo, pois fez com que cada participante mobilizasse outros saberes e colaborasse uns com os outros.

Considerando o que preconiza os regimes de interação, à princípio, atuamos como destinadores, seduzindo os destinatários docentes a um fazer mediante um querer. Para isso, partimos do currículo adotado pela escola-campo que define o blog como um dos gêneros a serem ensinados na turma do $7^{\circ}$ ano e, uma vez que os professores-participantes demonstravam

\footnotetext{
${ }^{5}$ Os dados apresentados nesta seção são, também, recorte do artigo "O Digital Como Estratégia De Ensino: Uma Abordagem Semiótica", que se encontra no prelo.
} 
pouca familiaridade com essa modalidade textual-discursiva, percebemos que o querer aprender foi determinante para a adesão ao blog.

Nesse sentido, os discursos dos professores-participantes revelam o querer fazer que se sobrepõe ao dever ou poder-fazer que, segundo Greimas (2008, p. 77) é o que torna a ação possível. Segundo Landowski (2014, p. 49), pela lógica da competência modal "um sujeito só pode ser, por definição, um sujeito de "vontade" (ou, mais geralmente, de intencionalidade), e manipular outro", se o destinador fazê-lo "querer" fazer (LANDOWSKI, 2014, p. 49). Considerando esse "sujeito de "vontade" é que passamos a doação de saberes aos destinatários através das quatro oficinas analisadas a seguir (RODRIGUES, 2015, p. 143, no prelo).

As experiências de escrita colaborativa com os professores em formação revelam sentimentos como a objeção advinda do medo, vinculado pela professora Cecília, ao fato de para alguns utilizar a tecnologia em sala de aula consiste em "enrolação". Já no discurso de Emmy: "Tem gente que tem medo de estragar porque não sabe usar" vemos que o não saber usar é que distancia a professora da tecnologia (RODRIGUES, 2015, p. 145, no prelo).

Ao propor uma discussão em torno da utilidade da tecnologia na escola, os discursos dos professores revelam as transformações quanto às crenças dos professores-participantes, ainda que medo e a certeza das dificuldades ainda fossem latentes: "É difícil, mas dá certo", “não é tão difícil assim”, diz Emmy. Essa transformação do crer é assinalada temporalmente, entre um antes e um agora, na fala de Emmy: “Agora vai ser mais fácil” (RODRIGUES, 2015, p. 145 , no prelo).

Destacamos ainda o discurso do professor Cabral que revela a transformação de estado pelos participantes da pesquisa que durante o processo foram modalizados pelo saber-fazer: "Muitas vezes a gente vê as coisas na tecnologia e se apavora (...) Tem que tentar né?!(...) Aí é assim, igual a gente, vê a tecnologia, a gente fica com medo". Os enunciados evidenciam a relação do sujeito actancial (querer-fazer) com o objeto (computador). Ao discursivizar a relação dos sujeitos com a tecnologia, Cabral tematiza a relação de disjunção que até pouco tempo atrás o representava motivada mais uma vez pelo "medo". Agora, revê sua própria rejeição, observando que repete um comportamento de seus alunos, que desistem antes de tentar aprender.

Os depoimentos denotam agora tanto a modalização pelo querer quanto a do saber. Ao longo do percurso da pesquisa participante, os professores-participantes demonstraram que 
embora vivessem em disjunção com o digital, havia um querer-fazer latente. Mas faltava crer, ou mesmo poder-fazer em detrimento das dificuldades existentes.

Em síntese, os discursos dos professores confirmam que ao longo do processo de intervenção, foram adquirindo novos saberes, deixando assim o seu estado inicial de medo, transformando-o em esperança quanto a usos futuros dos conhecimentos adquiridos em torno do blog, Google Docs, entre outros. A interação com o digital ressignificou os professoresparticipantes. Isso se comprova quando tomamos os discursos de Anne: "É sempre bom aprender coisas novas e levar para os alunos", e também Emmy "Eu estava pensando aqui de criar um blog para os meus alunos". Não podíamos prever as transformações dos actantessujeitos, mas testemunhar a sua competencialização foi um aprendizado que redimensionou a proposta inicial de intervenção (RODRIGUES, 2015, p. 164).

\section{Considerações finais}

E foi assim "desvendo" os sujeitos (professores e alunos) que fomos tomados pelo desejo de resposta às questões norteadoras apresentadas logo no início deste trabalho e que nos motivou a descobertas relevantes, dentre elas, que embora o digital tenha lugar na escola, fazse necessário a continuidade desta proposta, assim como a sua ampliação. O uso do blog como estratégia de ensino expandiu as perspectivas de interação entre os sujeitos da escola-campo, bem como dos sujeitos com a tecnologia mediados pelo uso do computador e o desenvolvimento de novos saberes.

Os professores-participantes passaram a reconhecer o potencial educacional que o blog possui e agora sabem operacionalizá-lo, embora ainda de maneira tímida. Em contrapartida, o fato de os participantes terem se deixado seduzir quanto ao uso das tecnologias digitais para fins educacionais representa o compromisso desses professores em repensar a sua prática e criar estratégias que levem os seus alunos a aprender. Assim sendo, temos consciência de que a pesquisa assumiu um papel transformador, pois culminou com a modalização dos sujeitos do querer e saber-fazer, ou seja, os professores aderiram às propostas de intervenção e se dispuseram a ampliar os saberes no que diz respeito ao uso do digital com fins educacionais.

Por tudo isso, indicamos à escola-campo a continuidade do trabalho com o blog mantendo a perspectiva interdisciplinar na qual se fundou desde a primeira intervenção e que sejam promovidas não só no âmbito da escola-campo, mas em todo o sistema municipal de ensino, uma formação voltada para o uso das tecnologias digitais na escola. Além disso, faz-se 
necessário maior investimento na instrumentalização das escolas para o uso do digital. A aquisição de equipamentos considerando a demanda a ser atendida é sem dúvida o maior desafio, porém, uma necessidade urgente. Faz-se necessário também, uma discussão acerca da proposta curricular que ainda não concebe os gêneros hipermidiáticos como estratégia de leitura e escrita com fins educacionais. Por fim, frisamos que concluímos esse trabalho gratificados pelas relevantes experiências partilhadas entre os participantes que exerceram de igual maneira, um papel significativo durante todo o processo transcorrido na pesquisa-ação. Fomos todos sujeitos desse processo e aprendemos e ensinamos reciprocamente.

Para concluir, nos valemos da história narrada por Anne quando avaliava a formação:

Ei Formadora, para resumir aqui o nosso curso, eu vou lhe contar a história que a gente aprende o tempo todo né? Geralmente, na nossa região, é costume que quando uma pessoa morre, é colocar uma velinha na mão, né. Aí estava um senhor lá no sertão, morrendo e tal e tal, e procuraram uma vela, uma lamparina, uma candeia e nada de achar nada para colocar na mãozinha dele né, na ânsia da morte. Aí tinha uma fogueira lá no meio do terreiro, aí um foi correndo lá e pegou uma brasa e colocou na mão dele, aí o velhinho foi e disse: "Ai, meu Deus, é morrendo e aprendendo" (Anne).

\section{Referências}

BORTONI-RICARDO, S. M. O professor pesquisador: introdução à pesquisa qualitativa. São Paulo: Parábola Editorial, 2008. p. 11-36.

BRANDÃO, C. R. A pesquisa participante e a participação da pesquisa: um olhar entre tempos e espaços a partir da América Latina. In: BRANDÃO, C. R; STRECK, D. R. Pesquisa participante: a partilha do saber. Aparecida, SP: Ideias et Letras, 2006

BUZATO, M. E. K. Entre a fronteira e a periferia: linguagem e letramento na inclusão digital. Campinas: Instituto de Estudos da Linguagem, 2007.

FIORIN, J. L. Elementos de análise do discurso. 14. ed., 1. reimp. São Paulo: Contexto, 2008.

FIORIN, J. L. Semiótica das paixões: o ressentimento. Alfa, São Paulo, v. 51, n. 1, p. 9-22, 2007.

FIORIN, J. L. Linguagem e interdisciplinaridade. Alea, Rio de Janeiro, v. 10, n. 1, p. 29-53, jan.-jun. 2008.

GREIMAS A. J. ; FONTANILLE, J. Entretien. In: Langue Française, n. 61, 1984. Sémiotique et enseignement du français. p. 121-128. Tradução: Luiza Helena Oliveira da Silva.

GREIMAS, A. J.; COURTÈS, J. Dicionário de semiótica. São Paulo: Contexto, 2008. 
KLEIMAN, Â. B. Preciso "ensinar" o letramento? Não basta ensinar a ler e escrever? Linguagem e letramento em foco: linguagem nas séries iniciais. Brasília: Ministério da Educação, 2005. Disponível em: $<$ http://www.iel.unicamp.br/cefiel/alfaletras/biblioteca professor/arquivos/5710.pdf $>$. Acesso em: 2 de set. 2015.

LANDOWISKI, E. Interações arriscadas. Trad. Luiza Helena Oliveira da Silva. São Paulo: Estação das Letras e Cores, 2014.

LANDOWISKI, E. Sociossemiótica: uma teoria geral do sentido. Galaxia (On-Line), São Paulo, n. 27, p. 10-20, jun. 2014. DOI: http://dx.doi.org/10.1590/1982-25542014119609.

LEMKE, J. L. Letramento metamidiático: transformando significados e mídias. Trab. Ling. Aplic., Campinas, p. 455-479, jul.-dez. 2010.

LÉVY, P. Cibercultura. Trad. Carlos Irineu da Costa. São Paulo: Ed. 34, 1999.

LIMA, M. C. A; VIEIRA, A. A. S. Escrita colaborativa na internet: a plataforma wiki. In: CELLMS, 3.; EPGL, 4.; EPPGL, 1., Dourados, 2007. Anais... s.p. Disponível em: $<$ http://www.uems.br/cellms/2008/documentos/09\%20-

\%20ESCRITA\%20COLABORATIVA.pdf>. Acesso em: 10 maio 2016.

ROJO, R. Letramentos múltiplos, escola e inclusão social. São Paulo: Parábola Editorial, 2009.

RODRIGUES, E. C. M. F. Práticas de letramento digital na escola: o blog como estratégia de ensino e formação de professores. 2015. 231f. Dissertação (Mestrado em Letras) - Programa de Mestrado Profissional em Letras, Universidade Federal do Tocantins, Araguaína, 2015.

SOARES, M. Letramento: um tema em três gêneros. 3. ed. 1. reimp. Belo Horizonte: Autêntica Editora, 2012.

SOARES, M. Novas práticas de leitura e escrita: letramento na cibercultura. Revista Educação e. Sociedade, Campinas, v. 23, n. 81, p. 143-160, dez. 2002.

XAVIER, A. C. S. Letramento digital e ensino. Disponível em: $<$ https://www.ufpe.br/nehte/artigos/Letramento $\% 20$ digital $\% 20 \mathrm{e} \% 20$ ensino.pdf $>$. Acesso em: 10 maio 2016. 